\title{
RESEARCH
}

Open Access

\section{GIS based quantification and mapping of climate change vulnerability hotspots in Addis Ababa}

\author{
Getnet Feyissa ${ }^{1 *} \mathbb{D}$, Gete Zeleke ${ }^{2,3}$, Ephrem Gebremariam ${ }^{4}$ and Woldeamlak Bewket ${ }^{5}$
}

\begin{abstract}
Background: Unlike the studies undertaken on agricultural and hydrological sectors, focused climate change vulnerability researches in urban centers in Ethiopia is not widely available and of recent history. However, as many signals of climate change vulnerability started to happen in urban centers as well, it is inevitable to analyze, quantify, map, prioritize and be prepared for adaptation measures. This study is therefore, tried to assess, quantify and map climate change vulnerability in Addis Ababa, Ethiopia, by integrating two climate change vulnerability assessment models, namely, the Sullivan and Meigh's Model of composite climate change vulnerability index and the IPCC's approach of vulnerability assessment which comprises exposure, sensitivity and adaptive capacity. Fifteen subcomponents of vulnerability indicators were identified in ten sub-cities (Addis Ketema, Arada, Akaki-Kality, Bole, Gulelle, Kirkos, Kolfe-Keraniyo, Lideta, Nifasilk-Lafto and Yeka) of Addis Ababa. Due to the scale, degree, amount and unit of measurement for the selected indicators varied, their values were normalized to a number which ranges between 0 and 1, indicating as the values increased to 1, vulnerability to climate change increases. The study uses lyengar and Sudarshan's unequal weighting system, to assign a weight to all indicators. The results were mapped using ArcGIS 10.2 package.

Results: The results indicated that the ten sub-cities in Addis Ababa were found in different levels of vulnerability to climate change. The exposure and sensitivity were highest for Addis Ketema, Arada, and Lideta which are found in central parts of the city, with a normalization index value greater than 0.5. The adaptive capacity index is the highest in Gulelle, Bole, and Arada sub-cities. These sub-cities have better quality houses, well-planned districts, good infrastructural facilities and good coverage of green areas compared to others. The overall climate change vulnerability was the highest (normalized index > 0.5) in Arada, Addis Ketema and Lideta, due to the adaptation capacity is the lowest compared to other sub-cities.

Conclusion: Addis Ababa is vulnerable to climate change impacts and the degree of vulnerability is underpinned by the interaction of multiple factors mainly adaptive capacities of sub-cities, location based characteristics and changes in climatic parameters. These present a need to strengthen mitigation and adaptation activities and prioritize sub cities for intervention based on the degree of vulnerability. It is also understood that the Sullivan and Meigh's Model and IPCC's approach for climate change analyses, could be used simultaneously for preparing vulnerability index per different geographical locations.
\end{abstract}

Keywords: Climate change, Exposure, Sensitivity, Sullivan and Meigh model, Vulnerability index

\footnotetext{
* Correspondence: getyonani@yahoo.com

${ }^{1}$ Ethiopian Institute of Architecture, Building Construction and City

Development (EiABC), Environmental Planning Programme, Addis Ababa

University, P.O. Box 518, Dej. Balcha Aba Nefso St, Addis Ababa, Ethiopia

Full list of author information is available at the end of the article
} 


\section{Background}

Climate change is a major problem in the world in the current century and it is the biggest and greatest challenge that humanity faced in the twenty-first Century. The recent fifth Assessment Report of the Intergovernmental Panel on Climate Change (IPCC 2014) indicated that each of the last three decades has been successively warmer at the Earth's surface than any preceding decade since 1850 . The globally averaged combined land and ocean surface temperature data as calculated by a linear trend show a warming of 0.85 [0.65 to 1.06$]^{\circ} \mathrm{C}$ over the period 1880 to 2012 . It is well accepted that climate change will have a far more detrimental effect on developing countries compared to developed countries; this is mainly because the capacity to respond to such changes is the lowest in developing countries. Moreover, it seems clear that vulnerability to climate change is closely related to poverty, as the poor are least able to respond to climatic stimuli (Srivastava 2015). The case is also true for Africa, as the continent is viewed as the most vulnerable region to climate variability and change. Regionally in East Africa studies indicate that in countries like Burundi, Kenya, Sudan and Tanzania people are hit high by the impacts of climate change (Hassaan et al. 2017; Mwangi and Mutua 2015; Shemsanga et al. 2010). In Ethiopia, within the last decades, high temperature values recorded in different parts of the country. Various General Circulation Models (GCMs) results also tell as the future change climatic elements will be high. For instance, the average future change for the whole of Ethiopia for three 30 -year periods with A2 emissions shows warming in all four seasons in all regions, with annual warming in Ethiopia by the $2020 \mathrm{~s}$ of $1.2{ }^{\circ} \mathrm{C}$ with a range of $0.7-2.3^{\circ} \mathrm{C}$, 2050s by $2.2{ }^{\circ} \mathrm{C}$, range $1.4-2.9{ }^{\circ} \mathrm{C}$ (Conway and Schipper 2011). So far some studies predict long-term future climate change situations that could prevail up to the end of this century in Ethiopia (McSweeney et al. 2010).

If the occurrence of climate change is real, it is a must to identify it's possible impacts and prepared for better adaptation mechanisms. In view of this, it is important to understand the concept of climate change vulnerability, identify indicators, quantify and map in order to have a better understanding and to implement quick interventions. Climate change is not a single concept by itself and rather it enclosed various concepts within it. In most cases, vulnerability, resilience, and adaptive capacity are the central concepts for the analyses and understanding of the impacts of climate change, because, together they provide a framework that links biophysical climate sensitivity to social and economic factors that mitigate or amplify the consequences of environmental changes. Vulnerability assessment and resilience is mainly analyzed with the topics like sustainability, hazards and climate change impacts (Malone 2009). Low resilience systems are intrinsically vulnerable to stress and shock, so in this sense increasing resilience reduces vulnerability (Folke et al. 2002). Vulnerability to a climatic stressor is essentially a composite of exposure, a degree of sensitivity to the stressor, and the ability of the exposed system to cope with the stressor. Vulnerability is mostly considered to be a local phenomenon that is investigated by local-scale studies in which the specific societal (and physical) situation can be taken into account much better than in a global-scale study(Doll 2009).

Mapping vulnerability hotspots of climate change in urban areas underpin climate change adaptation and mitigation policies and strategies in the contemporary world. It helps to figure out which places and people are the most vulnerable, as well as the degree of vulnerability and possible adaptation options (Gebreegziabher et al. 2016). Due to the potential of maps in depicting vulnerability hot spots is high, as it has strong visual elements and can easily be interpreted than text, its usage is increasing in different research groups and organizations (de Sherbinin 2014).

More specifically, vulnerability mapping helps to set three policy measures. First, it is used to specify long-term targets for the mitigation of climate change; second, to identify vulnerable places and people and to prioritize resource allocation for adaptation and to put adaptation measures (Fussel and Klein 2006). In climate change literature, two components of vulnerability are identified: internal and external dimensions (Gebreegziabher et al. 2016). The internal dimension refers to frailty, insecurity, and capacity to anticipate, cope with, resist and recover from adverse effects of shocks. The external dimension involves exposure to risks and shocks.

In Ethiopia, the impact of climate change is studied largely at country level in different sectors mainly emphasizing on the impacts of agricultural productivity and water sectors. These studies reveal that climate change and variability severely affect economic conditions livelihoods and agricultural production and food security, water resources and health (Gebregiziabhre et al. 2016, Legese et al. 2016, Tafesse et al. 2016, Melese 2016, Abebe and Kebede 2017, Amare and Simane 2017). The impact of climate change in urban scale is also studied in towns like Dire Dawa (Billi et al. 2015), Addis Ababa (CLUVA 2011; Cochrane and Costolanski 2013; Birhanu et al. 2016; Feyissa et al. 2018) indicating the identified cities are vulnerable to climate change impacts mainly flooding and urban heat.

Though these studies provide some useful insights in the area of vulnerability to climate change, and reflect the current efforts to understand the relationship between climate change and vulnerability, their scale of study is either at national level which is very coarse or at case-specific level which do not indicate the overall vulnerability conditions. This study is, therefore analyzes how compiled bio-physical and socio-economic as well as geographic factors determine the vulnerability to 
climate change in Addis Ababa, under different sub administration level (sub-cities). It analyses and construct vulnerabilty index at sub-city level, identify and map vulnerability hotspots. It also tries to know whether the vulnerability to climate change is spatially varied or not in one large city. In this regard, there is no prior studies available which integrates the IPCC's approach and Sullivan and Meigh's model for vulnerability assessmnet in Addis Ababa. The result of the study helps as an input for planners and different organizations which already starts imposing a number of policies, strategies and programs aimed at enhancing the adaptive capacity and reducing the vulnerability of the country to climate variability and change.

\section{Methods}

\section{Study area description}

Addis Ababa is found between $8^{\circ} 50^{\prime} \mathrm{N}$ to $9^{\circ} 5^{\prime} \mathrm{N}$ and $38^{\circ} 38^{\prime} \mathrm{E}$ to $38^{\circ} 54^{\prime} \mathrm{E}$. It is the capital and the largest city of Ethiopia, with a total projected population of 3.44 million people in 2017(Federal Democratic Republic of Ethiopia Central Statistical Agency 2013) and the administration of the city is divided into ten sub-cities. Addis Ababa is home to $25 \%$ of the urban population in Ethiopia and is one of the fastest growing cities in Africa. The city is a major growth corridor for the countries vision to become a middle income by 2025 . The city alone currently contributes approximately $50 \%$ towards the national Gross Domestic Product, highlighting its strategic role within the overall economic development of the country (World Bank 2015).

The city is located in the central highlands of Ethiopia covering an areal extent of about $527 \mathrm{~km}^{2}$ with an average elevation of $2600 \mathrm{~m}$ above mean sea level (asl). The altitude range extends from the highest peak at Mount Entoto which is $3041 \mathrm{~m}$ to 2051 mean above sea level at the lower part of Akaki plain. The topography is undulating and form plateau in the northern, western and southwestern parts of the city. Bole, Akaki, and south western part of the city is characterized by gentle morphology and flat land areas. An average maximum temperature for Addis Ababa in the last 60 years is $22.9^{\circ} \mathrm{C}$ and the average minimum temperature is $10.2{ }^{\circ} \mathrm{C}$. The average annual rainfall for Addis Ababa is $1184 \mathrm{~mm}$. The wet season is from June to mid-September. The urban area is endowed with three major rivers: Kebena, Little Akaki and Big Akaki rivers and numerous small streams. The population density varies from sub-city to sub-city. The highest density in Addis Ketema sub city $(37,215 \mathrm{p} / \mathrm{sk} . \mathrm{km})$ to the sparse density in Akaki-Kality sub-city (1832p/sk.km). All the sub-cities in the downtown have high population density compared to sub cities found in peripheral areas. Fast rate of urban expansion and built up area are rapidly increasing in Addis Ababa (Woldegerima et al. 2016), which were largely attributed to population pressure on the land, a rapidly growing infrastructure and poor land use planning (Teferi and Abraha 2017).The study area is presented in Fig. 1.

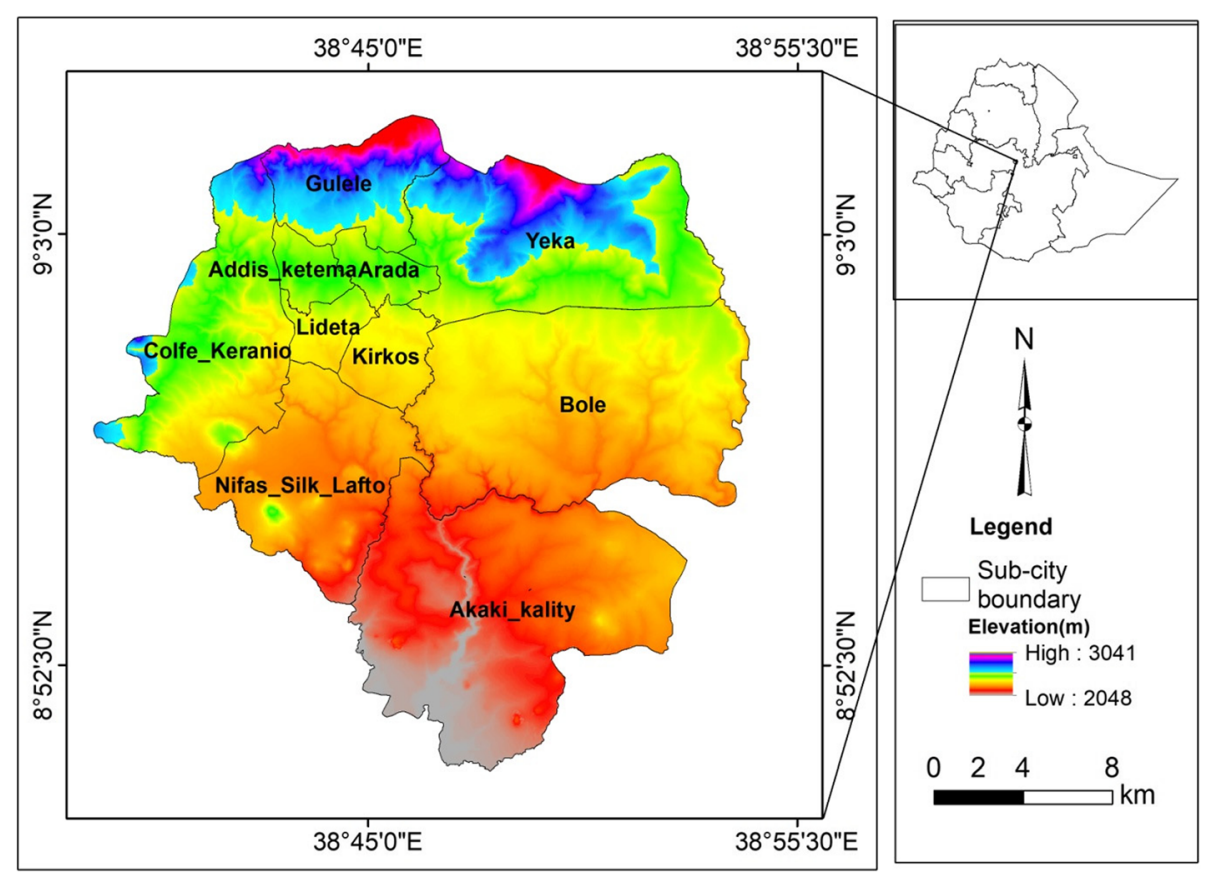

Fig. 1 Sub city boundary and Elevation map of Addis Ababa 


\section{Climate change vulnerability assessment approach}

Various vulnerability assessment methods are available for urban areas. For instance, the Climate change and Urban Vulnerability in Africa (CLUVA) project uses the vulnerability assessment for Addis Ababa based on the works done by Moser et al. 2010, based on asset, institution, attitude and physical as a collective umbrella of vulnerability.

According to the IPCC's definition, vulnerability to climate change and variability is represented by three elements: exposure, sensitivity, and adaptive capacity. Exposure can be interpreted as the direct danger (i.e., the stressor), and the nature and extent of changes to a region's climate variables (e.g., temperature, precipitation, extreme weather events). Sensitivity describes the human-environmental conditions that can worsen the hazard, ameliorate the hazard, or trigger an impact. Adaptive capacity represents the potential to implement adaptation measures that help avert potential impacts. Adaptive capacity is considered "a function of wealth, technology, education, information, skills, and infrastructure, access to resources, and stability and management capabilities" (Adger et al. 2005).

Therefore, analyzing vulnerability must involve identifying not only the threat but also the "resilience," or the potential responsiveness of the system and its ability to exploit opportunities and resist or recover from the negative effects of a changing environment. The first two components together represent the potential impact and adaptive capacity is the extent to which these impacts can be averted. Thus vulnerability is a potential impact (I) minus adaptive capacity (AC).

This leads to the following mathematical equation for vulnerability (International Crops Research Institute for the Semi-Arid Tropics 2009).

$$
\mathrm{V}=\mathrm{I}-\mathrm{AC}
$$

Which can be elaborated as follows (Moss et al. 2001):

$$
\text { Vulnerability }=(\text { adaptive capacity })-(\text { sensitivity }+ \text { exposure })
$$

This study uses eqs. 1 and 2 which stated above, and differentiates the indicators into three categories as exposure, sensitivity and adaptive capacity.

\section{Climate change vulnerability index}

Quantitative assessment of impact (vulnerability) is usually done by constructing a vulnerability index. This index is based on several sets of indicators that result in the vulnerability of a region. It produces a single number, which can be used to compare different regions (International Crops Research Institute for the Semi-Arid Tropics 2009). Various indexes have been developed to construct and map climate change vulnerability. This study uses indicator approach by integrating Climate change Vulnerability Index (CVI) model developed by Sullivan to construct climate change vulnerability index. This index is used as a checkup in indicator approach, whereas the weight is assigned in Arc GIS analyses.

Vulnerability assessment follows the standardized work done by Sullivan and adopted by many types of research due to it comprises various physical and socioeconomic data for urban areas. The methodology used for CVI is based on the methodology of Water Poverty Index developed by Sullivan and Meigh (2005) as specified in eq. 3 . The main components and subcomponents of vulnerability index developed by Sullivan and Meigh is presented in Table 1 .

$$
C V I=\frac{w_{r} R+w_{a} A+w_{c} C+w_{u} U+w_{e} E+w_{g} G}{w_{r}+w_{a}+w_{c}+w_{u}+w_{e}+w_{g}}
$$

$\mathrm{R}$ (Resources), $\mathrm{A}$ (Access), U(Use), C(Capacity), E(Environment), $G\left(\right.$ Geospatial), and $w_{r}, w_{a}, w_{u}, w_{c}, w_{e}, w_{g}-$ the weights of indicators.

However, slight modification can be done on the

\begin{tabular}{|c|c|}
\hline CVI Component & Sub Indicators \\
\hline Resource & Total water resource \\
\hline \multirow[t]{2}{*}{ Access } & Clean water \\
\hline & Sanitation \\
\hline \multirow[t]{6}{*}{ Capacity } & Education level of a population \\
\hline & Under five mortality rate \\
\hline & Income \\
\hline & People live in informal housing \\
\hline & Access to a place of safety in the event of flooding \\
\hline & Existence of disaster warning system \\
\hline \multirow[t]{3}{*}{ Use } & Domestic water use \\
\hline & Industrial water use \\
\hline & Agricultural water use \\
\hline \multirow[t]{4}{*}{ Environment } & Water stress \\
\hline & Water management \\
\hline & Population density \\
\hline & Loss of habitat \\
\hline \multirow[t]{5}{*}{ Geospatial } & Deforestation \\
\hline & Flood \\
\hline & Infrastructure \\
\hline & Thermal Heat Index \\
\hline & Land conversion from natural vegetation \\
\hline
\end{tabular}
Sullivan model based on the actual context of the study area. Considering the basic indicators of climate change 
vulnerability with minor modifications in Sullivan and Meigh Model 2005, the methodology followed is integrating IPCC's definition of vulnerability, in three sub layers of exposure, sensitivity and adaptive capacity. Every component is made up of sub-components. Based on these components, the 15 selected indicators presented on Table 2 were identified and analyzed for Addis Ababa.

\section{Normalization of the indexes}

Normalization of the indicators will undertake to ensure the comparability of the indicators. This was carried out using the methodology developed for the calculation of the $\mathrm{Hu}$ man Development Index (UNDP 2006) using eq. 4. Then all the indicators assigned with values range from 0 to 1 .

$$
X_{i j}=\frac{\mathrm{X}_{\mathrm{ij}}-\operatorname{Min}\left(\mathrm{X}_{\mathrm{ij}}\right)}{\operatorname{Max}\left(\mathrm{X}_{\mathrm{ij}}\right)-\operatorname{Min}\left(\mathrm{X}_{\mathrm{ij}}\right)}
$$

Where $\mathrm{X}$ is the separated value in the distribution, Min $\left(X_{i j}\right)$ is the minimum value in the distribution and $\operatorname{Max}\left(\mathrm{X}_{\mathrm{ij}}\right)$ is the maximum value of the mean of the distribution $i$ is the sub-city and $j$ is number of indicators. The value of the normalized equation falls between 0 and 1 . Where, 1 being the highest value and 0 with being the least vulnerable area for the indicators with positive relationship with climate changes vulnerability. Unless if the indicators are assumed to be negative relationship with vulnerability, the above formula will be changed to the following as described in eq. 5 .

$$
X_{i j}=\frac{\operatorname{Max}\left\{\mathrm{X}_{\mathrm{ij}}\right\}-\mathrm{X}_{\mathrm{ij}}}{\operatorname{Max}\left(\mathrm{X}_{\mathrm{ij}}\right)-\operatorname{Min}\left(\mathrm{X}_{\mathrm{ij}}\right)}
$$

Once the normalized scores have been completed for entire selected indicators the simple average construct vulnerability index by adding all normalized scores (eq. 6).

$$
V I=\frac{\sum_{j} x_{i j}+\sum_{j} y_{i j}}{K}
$$

Where VI is vulnerability index, $\mathrm{i}$ represent the sub-city and $j$ represents indicator and $K$ is the total number of indicators.

The value of the districts (i) is sub-cities and $j$ (indicators) is replaced with normalized CVI results in this study.

\section{Assigning weights to indicators}

The basic challenge in constructing indices is the lack of standard ways of assigning weight to each indicator. The two most common weighting methods used to combine indicators are equal and unequal weighting schemes (Gebreegziabher et al. 2016). The present study uses an unequal method of Iyengar and Sudarshan's 1982 to give weight to all indicators. The choice of the weights in this manner

\begin{tabular}{|c|c|c|c|c|}
\hline Component & Indicators & Functional Relation-ship & Layers in Sullivan Definition & Data Source \\
\hline \multirow[t]{3}{*}{ Exposure Layers } & Mean air temperature change & + & Geospatial & $\begin{array}{l}\text { National Meteorological } \\
\text { Agency }\end{array}$ \\
\hline & Change in Land surface Temperature & + & Geospatial & Extracted from Landsat \\
\hline & Flood Risk & + & Geospatial & $\begin{array}{l}\text { Constructed from different } \\
\text { layers }\end{array}$ \\
\hline \multirow[t]{3}{*}{ Sensitivity Layers } & Mud(wood) house type & + & Capacity & Central Statistical Agency \\
\hline & Population density & + & Environment & Central Statistical Agency \\
\hline & Vegetation cover & - & Environment & $\begin{array}{l}\text { Extracted from } 2017 \\
\text { Landsat }\end{array}$ \\
\hline \multirow[t]{9}{*}{ Adaptive capacity Layers } & Unemployment rate & + & Capacity & Central Statistical Agency \\
\hline & Literacy rate & - & Capacity & Central Statistical Agency \\
\hline & Under five mortality rate & + & Capacity & Central Statistical Agency \\
\hline & Activity Rate & & Capacity & Central Statistical Agency \\
\hline & Distance from emergency centers & + & Capacity & $\begin{array}{l}\text { Addis Ababa City Fire \& } \\
\text { Emergency Prevention \& } \\
\text { Rescue Authority }\end{array}$ \\
\hline & Road Length & + & Access & $\begin{array}{l}\text { Addis Ababa Road } \\
\text { Authority }\end{array}$ \\
\hline & Access to tap water & + & Access & Central Statistical Agency \\
\hline & Access to toilets & + & Access & Central Statistical Agency \\
\hline & $\begin{array}{l}\text { Distance from all type of health } \\
\text { centers }\end{array}$ & - & Access & $\begin{array}{l}\text { Integrated Land Information } \\
\text { and Technology Office }\end{array}$ \\
\hline
\end{tabular}
would ensure that large variation in any one of the

Table 2 Selected Indicators of Exposure, Sensitivity and Adaptive capacity and their data source 
indicators would not unduly dominate the contribution of the rest of the indicators and distort the overall ranking(Iyengar and Sudarshan 1982).

In Iyengar and Sudarshan's method, the weights are assumed to vary inversely as the variance over the regions in the respective indicators of vulnerability.

That is, the weight $w_{j}$ is determined by eq. 7 .

$$
W_{j}=C / \sqrt{\operatorname{Var}_{i}\left(X_{i j}\right)} .
$$

Where $C$ is a normalizing constant: (Eq. (8))

$$
[C=]\left[\sum_{j=1}^{j=k} 1 / \sqrt{\operatorname{Var}_{i}\left(x_{i j}\right)}\right]^{-1}
$$

The overall sub city index, $Y i$, also varies from zero (0) to one (1), with 1 indicating maximum vulnerability and 0 indicating no vulnerability at all. The higher the normalized sub-city index, the more the level of vulnerability. The composite indicator for climate change vulnerability factors (exposure, sensitivity and resilience) for the $i$ th sub city was obtained as:

$$
\sum W_{i} Y_{i j}
$$

Where: $Y i$ is the composite indicator of $i$ th sub-city; $W_{j}$ is the weight for each indicator lies between 0 and 1 ; $\sum W_{j=1} 1$ and $Y_{\mathrm{ij}}$ is the normalized scores of indicators.

\section{Zonal statistics}

The Zonal Statistics tool of ArcGIS was widely used in this study to assign values obtained from raster images to the sub-cities. A mean value of each indicator was computed for every zone (sub city). The average of the values in each zone is assigned to all output cells in the same zone. Zonal statistics tool is used in classifying and relating land surface in land use change in various studies (Youneszadeh et al. 2015; Rahmana 2016; Sierra-Soler et al. 2015). Based on the calculations, the land surface temperature changes with time and the elevation, their statistics and spatial correlations has been utilized. The application of GIS to analyze climate change vulnerability has grown exponentially in the last decade (Woodruff et al. 2017).

\section{Result}

\section{Analyses of exposure components}

Based on the climate vulnerability assessment procedure two major exposure layers were identified. These were temperature changes and flood risk layers. These layers are widely used in climate change exposure analyses.

A). Temperature Layers.
Under temperature change layers two sub-layers have been prepared. One is air temperature change layer, which obtained from direct measurement of meteorological stations and the other is the Land surface temperature change layer, which were derived from consecutive Landsat satellite images. Regarding the air temperature, three stations have been selected of five stations found in Addis Ababa based on the data availability and geographical variability. These were Entoto, Addis Ababa, and Bole observatories. The record at Entoto starts from 1989 onwards. Therefore the mean temperature record from 1989 to 2016 was divided into two parts for all the three stations. These are from (1989-2002) and from (2004-2016). The mean values of each station have been calculated and the first 14 years average was subtracted from the first mean value. Based on this, the temperature values had obtained, mapped and reclassified. The last final result was normalized. According to this, changes in mean temperature were $0.47{ }^{\circ} \mathrm{C}, 0.24{ }^{\circ} \mathrm{C}$ and $0.20{ }^{\circ} \mathrm{C}$ at Entoto, Addis Ababa observatory, and Bole respectively. The normalized scores were reclassified into five groups equally distributed with 0.2 normalized values range as presented in Fig. 2. Based on the Iyengar and Sudarshan's method of eq. 7, the attached weights are (0.3), (0.3) and (0.4) respectively for Land Surface Temperature Change, air temperature change, and flood risk. The assumption was that the places with the highest temperature change are more vulnerable to climate change. Identified exposure layers are presented in Table 3.

The mean difference of LST ranges from $3.4{ }^{\circ} \mathrm{C}$ at Addis Ketema to $0.8{ }^{\circ} \mathrm{C}$ at Yeka sub-city. The difference between the 1986 and 2017 has been normalized. Both results from air and land surface temperature change indicates that high rate of change is found in the northern and northwestern parts of Addis Ababa while the low elevated parts of Addis Ababa, which are sparsely populated have low rate and magnitude of change in temperature.

\section{B). Flood Risk Layers.}

The flood risk is not directly obtained as a single layer as explained in temperature case. Instead of considering a precipitation as a direct exposure layer in an urban area, it is better to integrate it with the flood risk layers. In order to get flood risk layers, four sub-layers has been weighted using multi-criteria evaluation. These four sub-layers are a) 2017 land cover layers obtained from land cover layers. The land cover layer has five land cover classes, namely built-up area; bare ground, open land, vegetation cover and agricultural land. b) Slope layers: the slope is divided into five classes $0-2 \%, 2-8 \%, 8-15 \%, 15-30 \%$ and greater than $31 \%$. 

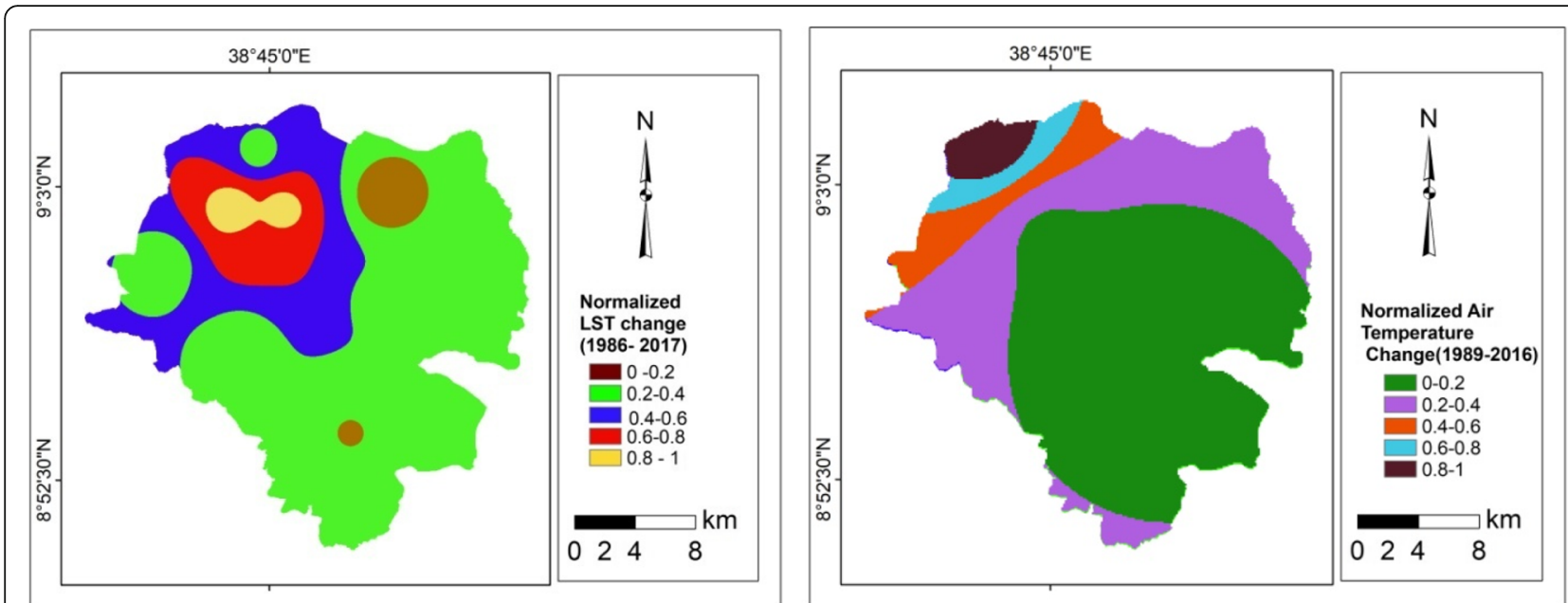

Fig. 2 Normalized LST and air temperature change

The slope layer is classified based on FAO, the highest slope value with fewer floods and the least with high probability to be hit by flooding. c) Drainage density layers: The drainage data is extracted from $30 \mathrm{~m}$ Digital Elevation Model (DEM of Addis Ababa. Up to six stream orders have been considered for the analyses. The drainage classes are $0-0.5 \mathrm{~km} / \mathrm{km}^{2}, 0.5-1 \mathrm{~km} / \mathrm{km}^{2}$, $1-1.5 \mathrm{~km}^{2}, 1.5-2 \mathrm{~km}^{2}$ and $>2 \mathrm{~km} / \mathrm{km}^{2}$. Drainage density has a positive relationship with flooding.

d) The soil layers: As surveyed by Ministry of Water and Energy in 2004, the soil classes in Addis Ababa are Classic Xerosols, Chromic Luvisols, Eutric Nitisols, Leptosols, Orthic Solonchaks and Pellic Vertisols (Gizachew Kabite: GIS and remote sensing based solid waste landfill site selection: A case of Addis Ababa city, Unpublished). The dominant soil of the region is Pellic Vertisol $\left(277.23 \mathrm{~km}^{2}\right)$ which is found in the Southern and North East part of the city. Eutric Nitisol $\left(111.55 \mathrm{~km}^{2}\right)$ is the second most dominant soil found in the central and North West part of the region. Vertisol is characterized by fine textured soil with $>60 \%$ clay in composition. As a result, the porosity of such soil is very fine making the movement of material difficult within the soil. Hence, the permeability of Vertisol is very low except within the cracks that are formed during dry seasons.

Leptosol is characterized by shallow depth underlined by hard rock and with less developed soil. The textural class is moderately coarse-textured soil with high permeability (Gizachew Kabite: GIS and remote sensing based solid waste landfill site selection: A case of Addis Ababa city, Unpublished). Soils with high permeability are assigned lesser weights in flood risk mapping. Based on

Table 3 Exposure Layers

\begin{tabular}{|c|c|c|c|c|c|c|c|c|}
\hline & LST $\left({ }^{\circ} \mathrm{C}\right) 1986$ & LST $\left({ }^{\circ} \mathrm{C}\right) 2017$ & Mean & Air Te & serature $\left({ }^{\circ} \mathrm{C}\right)$ & & & \\
\hline & Mean & Mean & Difference & Nor. & Mean Temp $\left({ }^{\circ} \mathrm{C}\right)^{\mathrm{a}}$ & Mean Temp $\left({ }^{\circ} \mathrm{C}\right)^{\mathrm{b}}$ & Mean Difference & Nor. \\
\hline Arada & 24.5 & 27.7 & 3.2 & 0.92 & 16.64 & 16.91 & 0.27 & 0.22 \\
\hline Addis Ketema & 24.2 & 27.6 & 3.4 & 1.00 & 16.18 & 16.48 & 0.30 & 0.39 \\
\hline Lideta & 25.2 & 27.9 & 2.7 & 0.73 & 17.05 & 17.30 & 0.25 & 0.11 \\
\hline Kirkos & 25.3 & 27.7 & 2.4 & 0.62 & 17.06 & 17.30 & 0.24 & 0.06 \\
\hline Nifas Silk & 26.6 & 28.0 & 1.4 & 0.23 & 16.65 & 16.90 & 0.25 & 0.11 \\
\hline Akaki-Kality & 27.9 & 29.2 & 1.3 & 0.19 & 16.67 & 16.91 & 0.24 & 0.06 \\
\hline Bole & 26.7 & 28.4 & 1.7 & 0.35 & 16.82 & 17.05 & 0.23 & 0.00 \\
\hline Yeka & 25.1 & 25.9 & 0.8 & 0.00 & 16.09 & 16.38 & 0.29 & 0.32 \\
\hline Gulelle & 22.4 & 24.0 & 1.6 & 0.31 & 14.04 & 14.45 & 0.41 & 1.00 \\
\hline Kolfe & 25.3 & 26.7 & 1.4 & 0.23 & 15.92 & 16.23 & 0.31 & 0.44 \\
\hline
\end{tabular}

${ }^{a}$ Averaged mean air temperature record from (1989-2002) interpolated from Entoto, Addis Ababa, and Bole observatories, and derived for each sub city using Zonal Statistics

${ }^{\mathrm{b}}$ Averaged mean air temperature record from (2003-2016) interpolated from Entoto, Addis Ababa, and Bole observatories, and derived for each sub city using Zonal Statistics (Source: Based on data from Landsat and National Meteorological Service, constructed by authors) 

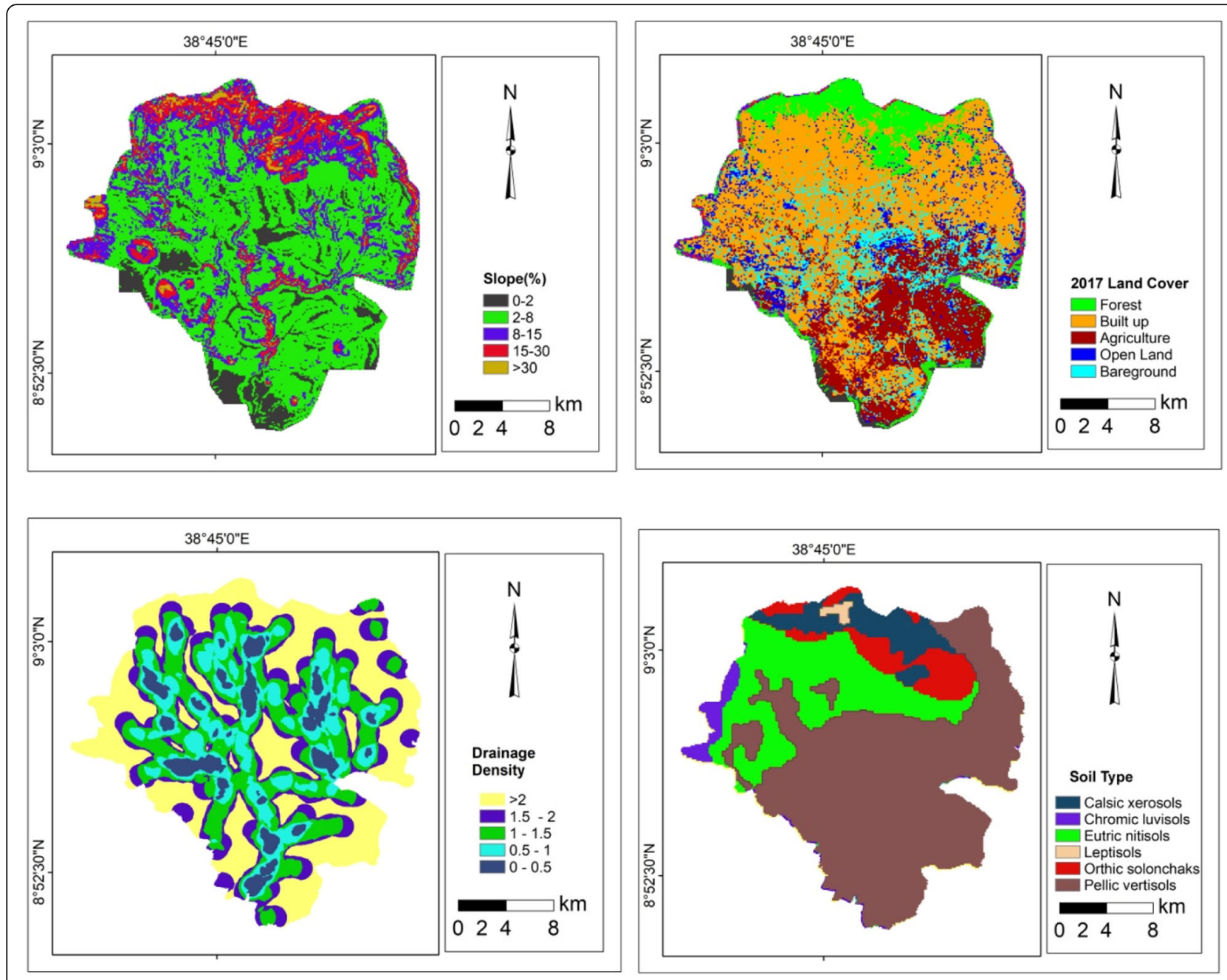

Fig. 3 Layers weighted for flood risk

these the highest value is assigned for Vertisol and the least value is assigned for Leptisol. In general $30 \%, 25 \%$, $30 \%$, and $15 \%$ weight factor is assigned for land cover, slope, drainage density, and soil type respectively to get flood risk map of Addis Ababa. Flood layers are presented in Fig. 3.

The final flood risk map was divided into five layers, from low to very high flood risk categories. The area coverage percentage of very high risk and the high-risk were summed together to categorize the sub-cities. Based on the criteria, the sub-cities fall under risk areas were Arada, Lideta, Addis Ketma, Kirkos and Akaki, which have large parts of their land fall under flood risk. The final flood risk map showed that areas with highest population density and lowest elevation as well as high drainage density have a highly exposed to climate change. The upper parts of the city which is covered by forest had low flood risk while the places along the drainage basins and high-density areas had highest flood risk.The food risk map is presented in a systematic manner from high risk to very low risk as depicted in Fig. 4. The same approach is used for flood risk mapping by various authors(Olatona 2017; Ouma and Tateishi 2014).

General exposure index indicates that the highest exposure were in Addis $\operatorname{Ketema}(0.72), \operatorname{Arada}(0.66)$ and Lideta(0.5). Moderate exposure were in $\operatorname{Kirkos}(0.45)$, and Gulelle(0.49).Others sub-cities have low exposure index value. The least exposure was in Bole(0.135).

The flood hazard map prepared from the composite layers of drainage density, soil, population density and slope at the exposure layer of this analysis was well integrated with the actual data recorded on flood history. The flood history has been collected from the Addis Ababa fire and emergency preparedness office from 2010 to 2016. The GPS points where flood history is recorded in the past 8 years has been taken and overlaid as indicated in Fig. 4. 


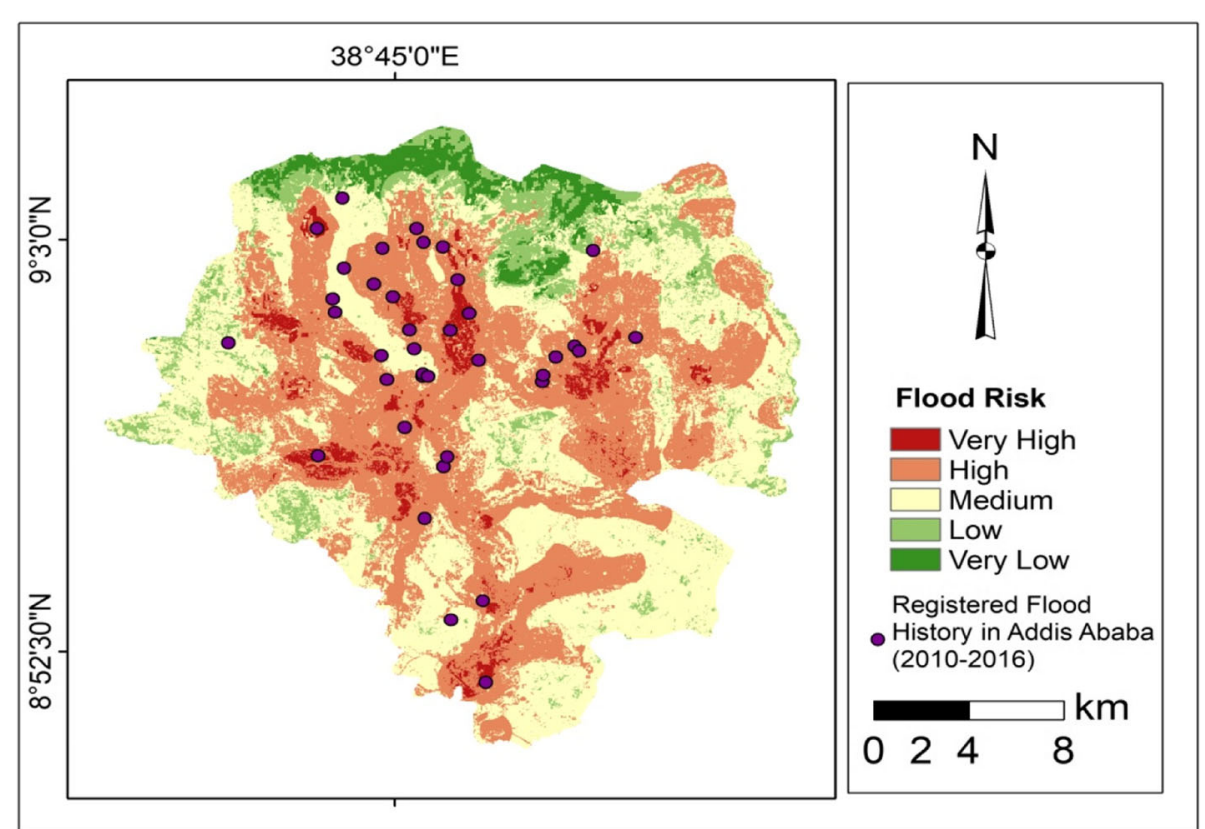

Fig. 4 Flood risk map overlaid by frequency of flood Hazard records in Addis Ababa (Source:Data from Addis Ababa Fire and Emergency Service, compiled and constructed by authors)

\section{Sensitivity components}

Three layers have been identified for sensitivity component based on the criteria set by different authors and literature. These were the population density, the house type, and the vegetation cover. Similar indicators have been used for sensitivity analyses (Gebreegziabher et al. 2016; Zurovec et al. 2017). High population density was at Addis Ketema $\left(37,215 / \mathrm{km}^{2}\right)$ and sparsely populated at Akaki-Kality(1832) in 2017 as projected by Central Statistical Authority. Regarding the house types, the housing and population census have put different house types which include corrugated iron sheets, concrete/cement, thatch, wood and mud, bamboo, plastic, asbestos, and others. For the analyses, only house types constructed of mud and wood have been selected. Most parts of Addis Ababa had the houses constructed from mud and wood. Arada, Addis Ketema, Kirkos are the sub-cities with the majority of their houses are constructed by mud and wood. A well-planned sub city like in Bole sub-city, the main house constriction type is concrete. It is assumed that houses constructed by mud are highly sensitive to climate change and can't resist change-induced impacts like heavy rainfall than concrete building houses. The third subcomponent of sensitivity layer is forest cover layer. It is extracted from 2017 Landsat image. The land cover analyses indicates that Yeka and Gulelle sub cities had a high area of forest cover while Addis Ketema, Arada, Kirkos, and Lideta have a small proportion of vegetation covers. Places covered by forests are less sensitive to climate change. Based on these three layers one final layer is obtained. Accordingly highly sensitive, moderately sensitive and less sensitive areas have been identified. The sensitivity is low in sparsely populated areas, in open spaces and for buildings constructed by a standard material. The population density, the area of places covered by forest and the house type share per sub city is presented in Table 4.

The attached weights for each the three sensitivity layers were $0.32,0.32$ and 0.35 respectively for population density, forest coverage and houses constructed by mud and wood ( Fig. 5).

Based on the weights, the highest sensitivity was in Addis ketema, Arada and Lideta,with very high sensitivity index greater than 0.8 , high sensitivity index is in Kirkos(0.69), the medium sensitivity is in Nefassilk Lafto, Kolfe, Akaki-Kality, and Gulelle with sensitivity index from 0.4 to 0.6. Yeka and Bole had a lowest sensitivity index(0.2-0.4).

\section{Adaptive capacity components}

Nine adaptive capacity layers have been identified. These adaptive capacity layers were categorized into three sub-layers. These are socio-economic and demographic layers, access layers, and density and distance layers. a) The socio-economic layer consists of the unemployment rate, activity rate, literacy rate and under-five mortality rates. The data were used based on the 2007 Ethiopian housing and population census's definition. The percentage of socio-economic and demographic layers, per sub-cities, is presented in Table 5.

b) Access to Social Services. 
Table 4 Sensitivity Layers

\begin{tabular}{|c|c|c|c|c|c|c|}
\hline \multirow[t]{2}{*}{ Sub City } & \multicolumn{2}{|c|}{ Population Density (2017 projected) } & \multicolumn{2}{|c|}{ Forest Area(sq.km) } & \multicolumn{2}{|c|}{ Houses Constructed by Wood and Mud } \\
\hline & Pop density & Normalized & $\overline{\left(\mathrm{Km}^{2}\right)}$ & Normalized (-ve relation) & Percent & Normalized \\
\hline Arada & 28,206 & 0.75 & 0.08 & 1.00 & 81.2 & 0.77 \\
\hline Addis Ketema & 37,215 & 1.00 & 0.07 & 1.00 & 88.4 & 1.00 \\
\hline Lideta & 27,483 & 0.72 & 0.02 & 1.00 & 84.3 & 0.87 \\
\hline Kirkos & 18,996 & 0.49 & 0.04 & 1.00 & 76.5 & 0.62 \\
\hline Nifas Silk & 6812 & 0.14 & 0.22 & 0.99 & 66.5 & 0.31 \\
\hline Akaki-Kality & 1832 & 0.00 & 0.42 & 0.99 & 80.7 & 0.76 \\
\hline Bole & 3283 & 0.04 & 0.41 & 0.99 & 56.7 & 0.00 \\
\hline Yeka & 5292 & 0.10 & 27.35 & 0.00 & 82.7 & 0.82 \\
\hline Gulelle & 10,751 & 0.25 & 15.63 & 0.43 & 87.5 & 0.97 \\
\hline Kolfe & 8479 & 0.19 & 4.43 & 0.84 & 76.3 & 0.62 \\
\hline
\end{tabular}
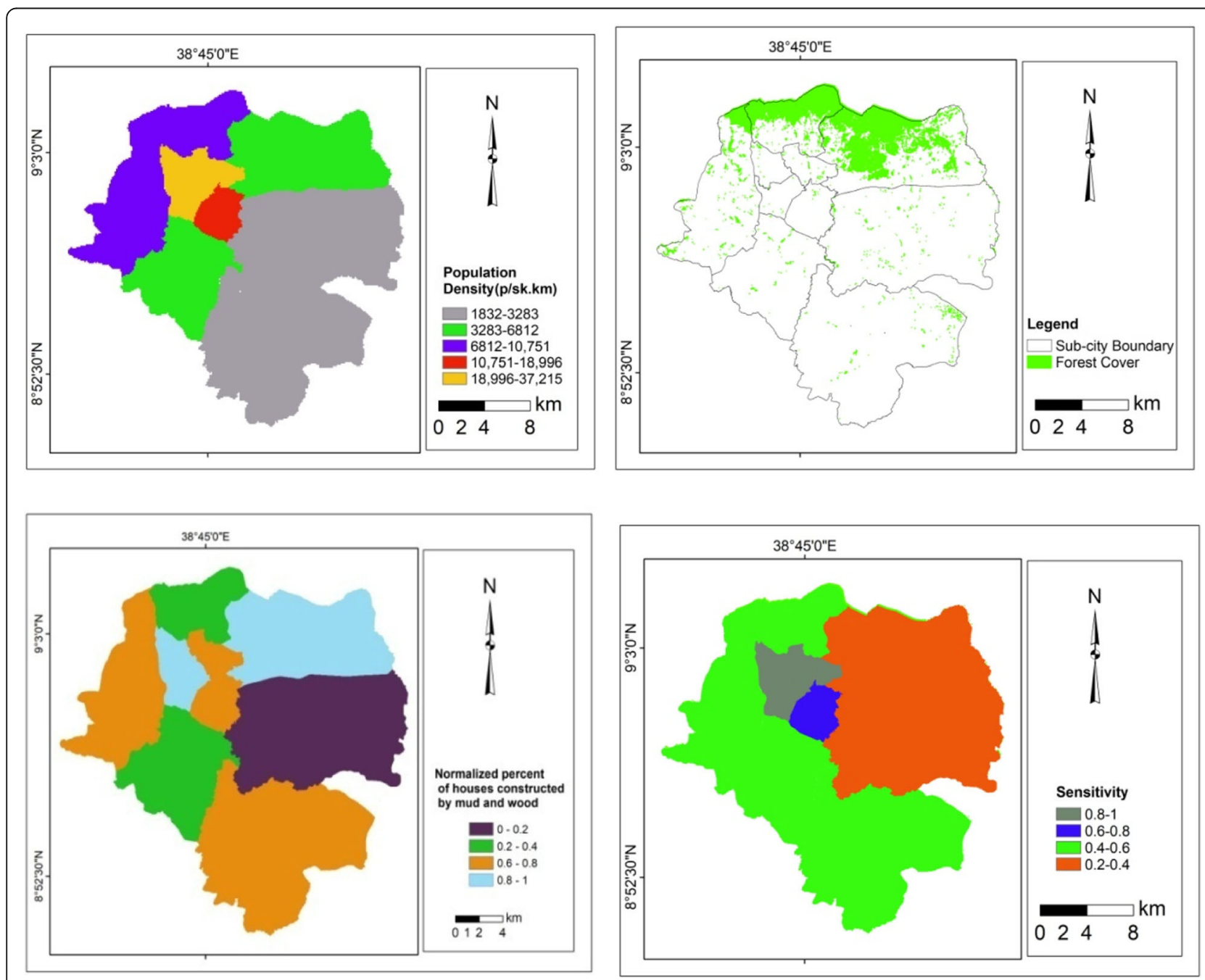

Fig. 5 Sensitivity Layers 
Table 5 Percentage and normalized values of socio economic and demographic data

\begin{tabular}{|c|c|c|c|c|c|c|c|c|}
\hline \multirow[t]{2}{*}{ Sub City } & \multicolumn{2}{|l|}{ Literacy } & \multicolumn{2}{|c|}{ Under five Mortality } & \multicolumn{2}{|c|}{ Unemployment } & \multicolumn{2}{|l|}{ Activity } \\
\hline & Rate (\%) & Normalized & Rate (\%) & Normalized & Rate (\%) & Normalized & Rate (\%) & Normalized \\
\hline Arada & 89.3 & 0.00 & 0.05 & 0.33 & 24.2 & 0.68 & 63.8 & 0.51 \\
\hline Addis Ketema & 84.0 & 0.77 & 0.03 & 0.11 & 27.2 & 1.00 & 62.8 & 0.35 \\
\hline Lideta & 86.0 & 0.48 & 0.04 & 0.16 & 26.2 & 0.89 & 63.4 & 0.45 \\
\hline Kirkos & 88.8 & 0.07 & 0.03 & 0.06 & 21.2 & 0.37 & 64.1 & 0.55 \\
\hline Nifas silk & 85.4 & 0.57 & 0.02 & 0.01 & 21 & 0.35 & 63.1 & 0.40 \\
\hline Akaki-Kality & 82.4 & 1.00 & 0.05 & 0.31 & 20.3 & 0.27 & 60.5 & 0.00 \\
\hline Bole & 84.1 & 0.75 & 0.02 & 0 & 17.7 & 0.00 & 67 & 1.00 \\
\hline Yeka & 86.0 & 0.48 & 0.10 & 1 & 23.4 & 0.60 & 62.6 & 0.32 \\
\hline Gulelle & 85.0 & 0.62 & 0.05 & 0.42 & 20.8 & 0.33 & 62.6 & 0.32 \\
\hline Kolfe & 83.7 & 0.81 & 0.04 & 0.27 & 23.5 & 0.61 & 63.3 & 0.43 \\
\hline
\end{tabular}

There are many access data that has to be considered for climate change vulnerability. However, in order to avoid bias, only two data, which are fully available and complete for all sub cities were considered to analyze access. These are a percentage of access to water (only access to water provided by tap both in their house or compound whether it is shared or private) and percentage of access to toilets for sanitation layer. c) Distance and Density Data: The two layers of distance (distance from the health center and distance from emergency controlling center) have been analyzed. The health centers include both private and government health centers, all types of clinics and all types of hospitals. The distance from emergency controlling centers data indicates that the average distance of each place in the sub-city from the Addis Ababa fire and emergency controlling center. The road density layer data was obtained by adding all types of road lengths and dividing it to the area of the sub-city. The types of roads considered in these analyses are asphalt, large stone, gravel, earth, and cobble stone. The distance and density layers are presented in Fig. 6. Details of the adaptive capacity data with their normalized value per sub-cities are given in Table 6 .

Finally as depicted on Table 7, the weights has been assigned to the indicators.

The final adaptive capacity index indicates Bole(0.56) was the highest sub city in adaptive capacity. Kolfe(0.48), Addis Ketema(0.43), Kirkos(0.43) and Nifas Silk(0.41) and Akaki-Kality (0.40). Addis have moderate adaptive capacity. Arada, Lideta,Yeka and Gulelle are sub cities with low adaptive capacity. The adaptive capacity map of Addis Ababa is presented on Fig. 7.

The final vulnerability index, determined by composite indicators of exposure, sensitivity and adaptive capacity indicates that sub cities with a normalized vulnerability index value more than 0.5 were $\operatorname{Arada}(0.63)$, Addis Ketema(0.60), Gulelle(0.53), Kirkos(0.52) and Lideta(0.5). Bole(0.45), Kolfe Keranio(0.4)and Nifas silk(0.37) were moderately vulnerable, while Yeka(0.33) and $\operatorname{Akaki-Kality(0.30)}$ were least vulnerable sub cities based on the 15 climate change vulnerability indicators(Table 8 ).

\section{Discussions}

Climate change impact is not measured only by the exposure and sensitivity's strength; rather, it is a matter of adaptive capacity. The exposure layers selected for vulnerability analyses in Addis Ababa was lower, but the sensitivity was high and adaptive capacity activities were low. These altogether makes Addis Ababa to be vulnerable city to climate change. The distribution of exposure layers which contains physical factors was different. For instance the air and LST temperature changes to the central and northern part of the city is high, indicating the higher of the sensitivity and the lower value of adaptive capacity in that parts. Addis Ketema and Arada sub cities, which contained the oldest buildings within them, have old roofed houses, limited green area coverage's and poorly managed streets with no street trees. These all makes the exposure to climate change in this part to be high.

In contrast to this, the sub-cities with high rise building, but with more planned parcels of land like in Bole and most parts of Yeka had lower-temperature change. Another important and influential exposure indicator which has high factor in Addis Ababa was flooding. Floods, the most prevalent of natural risks, are anticipated to happen more strictly and regularly in the future because of climate change (Nasiri and Shahmohammadi-Kalalagh 2013). Flood as exposure layer plays a key role in Addis Ababa, mainly in the southern and south eastern parts of the city due to the gentle slope characteristics of the relief in these parts. The past record on flooding in Addis Ababa indicates, it was increasing from time to time. There are a wide evidence that the flooding in Addis will be continue to increase to the end of this century due to climate change (CLUVA 2011; Ward and Lasage 2009; McSweeney et al. 2010; Feyissa et al. 2018) and poor urban storm water management in Addis Ababa. The exposure layer of climate 


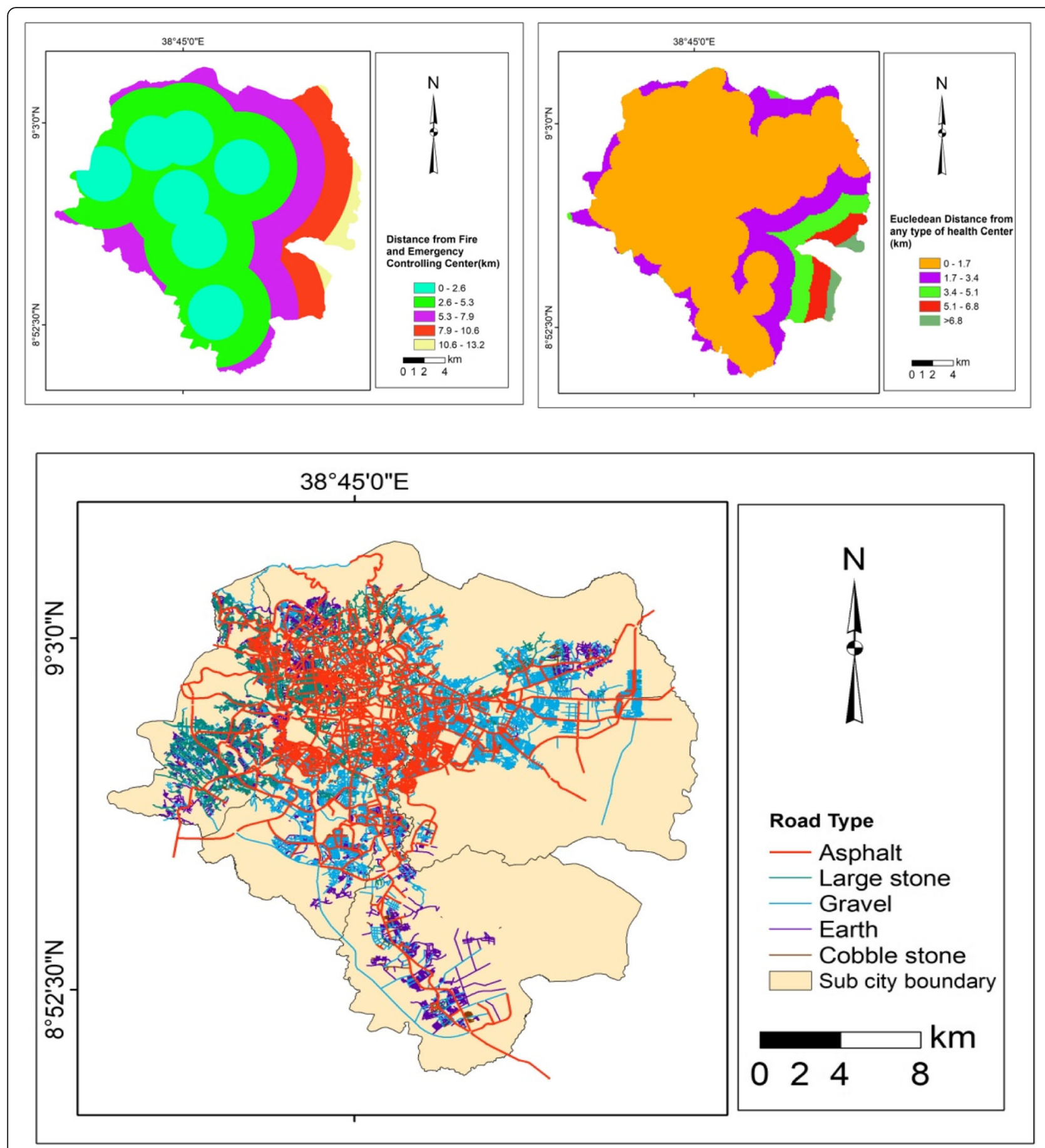

Fig. 6 Adaptive capacity layers (distance and road)

change vulnerability identified in these analyses indicates the flood is common in poor infrastructure areas, low quality housed but dense population along streams. Flooding is common in Kirkos, parts of Bole and Akaki, at a time of heavy rain. The topographic nature of the southern and south western are gentle, and the heavy rain drops from mountains flow to the southern direction, makes the
Akaki-Kality area to be more vulnerable to flooding. Climate change vulnerability activities and the vulnerability to flooding is more aggravated due to a poor drainage system, rapid housing development along river banks and using inappropriate construction material(Birhanu et al. 2016; Belete 2011). The estimated cost of damage in Addis Ababa was 373,640 million birr, 1.3 million birr and 1.3 million 
Table 6 Adaptive Capacity: Access, distance and density Data

\begin{tabular}{|c|c|c|c|c|c|c|c|c|c|c|}
\hline \multirow[b]{3}{*}{ Sub City } & \multicolumn{4}{|c|}{ Access Data } & \multicolumn{6}{|c|}{ Distance and Density } \\
\hline & \multicolumn{2}{|c|}{ Access to safe drinking water } & \multicolumn{2}{|c|}{ Access to sanitation } & \multicolumn{2}{|c|}{ Distance from ECC } & \multicolumn{2}{|c|}{ Distance from Health Centers } & \multicolumn{2}{|l|}{ Road } \\
\hline & $(\%) \operatorname{tap}^{a}$ & Norm & (\%) Of toilet & Nor. & Mean Dist. & Norm. & Mean Dist. & Norm. & Road Dens. & Norm \\
\hline Arada & 68.53 & 0.60 & 90.66 & 1.00 & 5.684 & 0.95 & 0.64 & 0.26 & 9.69 & 0.80 \\
\hline Addis Ketema & 55.61 & 0.00 & 87.29 & 0.73 & 3.753 & 0.54 & 0.26 & 0.04 & 5.98 & 0.42 \\
\hline Lideta & 65.91 & 0.48 & 87.75 & 0.77 & 2.293 & 0.23 & 0.89 & 0.41 & 3.10 & 0.12 \\
\hline Kirkos & 73.19 & 0.82 & 90.31 & 0.97 & 3.090 & 0.40 & 0.25 & 0.03 & 11.58 & 1.00 \\
\hline Nifas silk & 77.00 & 1.00 & 86.12 & 0.63 & 2.083 & 0.19 & 0.76 & 0.33 & 6.95 & 0.52 \\
\hline Akaki-K. & 65.33 & 0.45 & 78.25 & 0.00 & 4.066 & 0.61 & 2.10 & 1.0 & 1.9 & 0.00 \\
\hline Bole & 72.03 & 0.77 & 83.38 & 0.41 & 5.930 & 1.00 & 0.19 & 0.00 & 2.78 & 0.09 \\
\hline Yeka & 71.65 & 0.75 & 84.97 & 0.54 & 1.368 & 0.04 & 2.06 & 1.09 & 4.46 & 0.26 \\
\hline Gulelle & 73.11 & 0.82 & 84.74 & 0.52 & 4.688 & 0.74 & 0.25 & 0.03 & 8.60 & 0.89 \\
\hline Kolfe & 68.64 & 0.61 & 84.98 & 0.54 & 1.197 & 0.00 & 2.10 & 1.0 & 6.81 & 0.51 \\
\hline
\end{tabular}

${ }^{a} \%$ of tape inside the house, in compound private and tap in compound shared

ECC emergency controlling center (Fire and Emergency Prevention and Rescue Agency)

birr in 2010, 2011 and 2012 respectively. Many of the costs of the recent flood damage, for instance flood damage occurred in 2006 was not estimated. Majority of the damages were occurred in the months of August and September as well as in July. The stated Akaki-Kality and Kirkos were the highest affected by flooding in Addis Ababa, due to their plain elevation and over-crowded of old houses. Bole and Gullelle sub-cities had also high flood damage, while Addis Ketema Yeka, and Lideta are the moderately affected. Nefas silk Lafto, Arada and Kolfe Keraniyo sub-cities were the least affected sub cities(Fig. 8).

The higher sensitivity of the sub-cities to climate change emanated from higher density, low quality of constructed houses and low level of infrastructure development. These areas are mainly found in the central parts of the city, which have a high population density mainly in Addis Ketema, Lideta and Arada sub cities. In sensitivity values, variations were being observed among sub cities. Well planned, places with a good proportion of green area coverage and places with good construction materials were less sensitive to climate change impacts. The predominant use of mud and wood for the construction of house walls and floors calls for frequent repairs, which tend to be expensive in the long run. The households that have the highest use of these materials are in Akaki-Kality and Addis Ketema where the highest need for repairs was also apparent. In addition, dust

Table 7 Weights of Adaptive capacity layers

\begin{tabular}{llllllllll}
\hline Indicators & 1 & 2 & 3 & 4 & 5 & 6 & 7 & 8 & 9 \\
\hline Weight & 0.11 & 0.12 & 0.11 & 0.14 & 0.13 & 0.12 & 0.10 & 0.08 & 0.09 \\
Total & & & & & & & & & \\
\hline
\end{tabular}

Literacy Rate(1),Under five Mortality Rate(2),Unemployment Rate(3),Activity Rate(4), Access to tap(5), Access to toilets(6), Distance from emergency(7), Distance from health centers(8),Road Density(9), from the mud and earth used for the floors and walls leads to increased susceptibility of the dwellers to respiratory diseases, especially among children (UN Habitat 2003). This is the reason why sub city like Bole is less sensitive than Addis Ketema and Arada. Households in slum areas usually occupy non-durable dwelling units that expose them to high morbidity and mortality risks (UN Habitat 2003). Exposure and sensitivity are almost inseparable properties of a system (or community) and are dependent on the interaction between the characteristics of the system and on the attributes of the climate stimulus. The exposure and sensitivity of a system to an environmental related risk reflect the general conditions and characteristics of the system. (Smit and Wandel 2006). The highest proportion of green area coverage in Yeka $\left(15.63 \mathrm{~km}^{2}\right)$ and Gulelle $\left(15.63 \mathrm{~km}^{2}\right)$ in line with their geographical position within the city, makes them to have lowest sensitivity to climate change. In addition due historical reasons, the development of botanic gardens in this area, the rehabilitation of forest is high.

The low level of socio-economic, demographic and access to facilities in Addis Ababa made the adaptive capacity, to be low. Literacy rate and under five mortality rate as well as the higher unemployment rate also indicated the low level of the community's adaptation capacity to climate change. The low level of access layers, to social services like toilets and tap water were also the lowest. Another important layer in adaptive capacity, which has a greatest influence on the adaptive capacity layer, is the distance from the disaster controlling center. Most parts, mainly the peripheral sub cities had the highest distance from disaster controlling center. The infrastructural development, used at the time of early warning and hazard was also an important factor; 

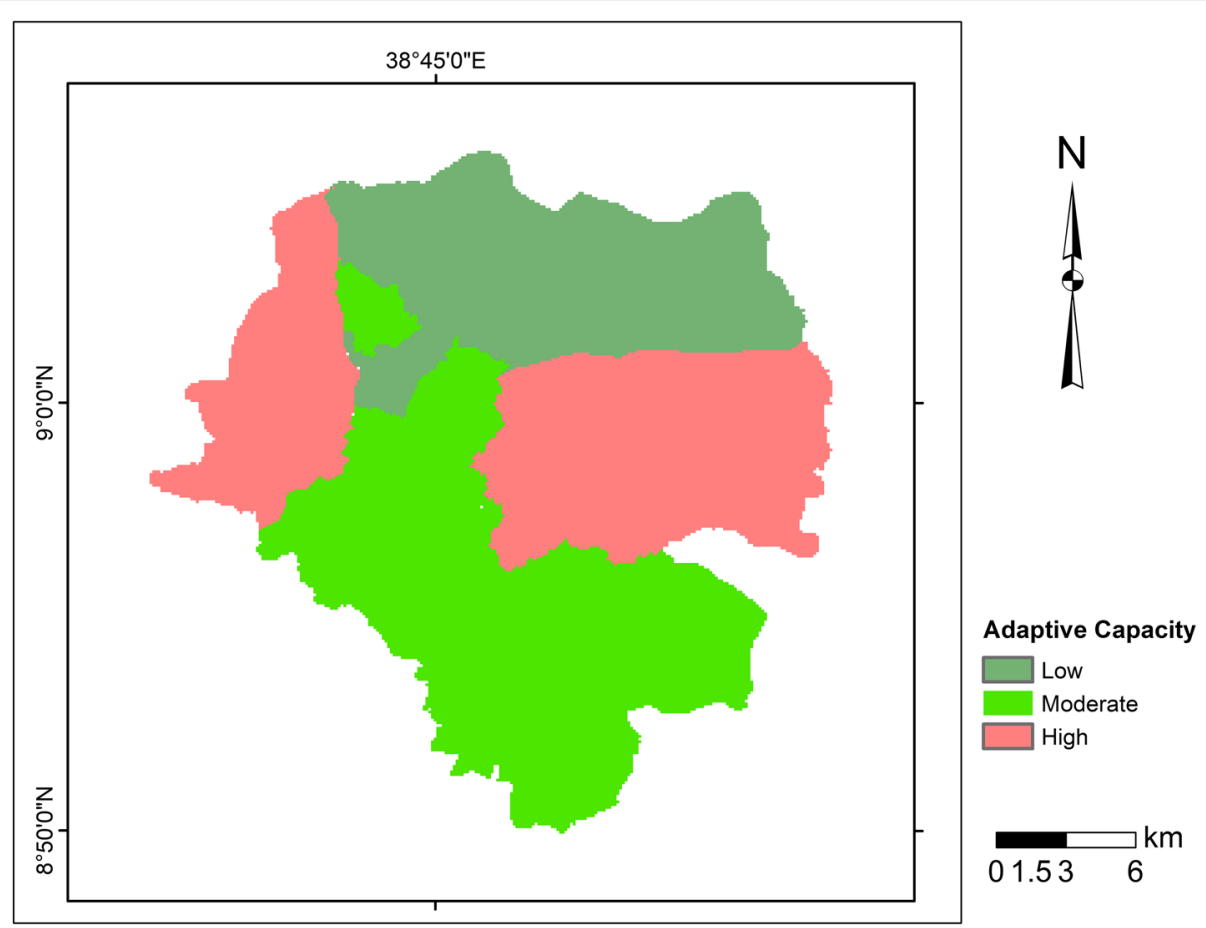

Fig. 7 Adaptive Capacity Map

which makes the adaptive capacity to be lower. The sub-cities with have low adaptive capacities are well vulnerable to climate change. Due to rapid urbanization and population increase, low-income communities are forced to settle in flood-prone areas additionally the poor drainage systems of the city also intensify the risk of flooding as well. Lacks of adaptation to climate change have increased vulnerability (Cochrane and Costolanski 2013). It is based on the adaptive capacity, whether any type of climate-related impact occur, it is based on its adaptive capacity whether it was a resilient or not. The vulnerability in Addis Ababa was exacerbated bylow level

Table 8 Normalized Exposure, Sensitivity and Adaptive Capacity layers

\begin{tabular}{|c|c|c|c|c|c|c|c|c|c|c|c|c|c|c|c|}
\hline & \multicolumn{3}{|c|}{ Exposure } & \multicolumn{3}{|c|}{ Sensitivity } & \multicolumn{8}{|c|}{ Adaptive Capacity } & \multirow[b]{2}{*}{15} \\
\hline & 1 & 2 & 3 & 4 & 5 & 6 & 7 & 8 & 9 & 10 & 11 & 12 & 13 & 14 & \\
\hline Arada & 0.92 & 1 & 0.22 & 0.75 & 1.00 & 0.77 & 0.00 & 0.33 & 0.68 & 0.51 & 0.60 & 1.00 & 0.95 & 0.26 & 0.80 \\
\hline Addis K. & 1.0 & 0.87 & 0.39 & 1.00 & 1.00 & 1.00 & 0.77 & 0.11 & 1.00 & 0.35 & 0.00 & 0.73 & 0.54 & 0.04 & 0.42 \\
\hline Lideta & 0.73 & 0.8 & 0.11 & 0.72 & 1.00 & 0.87 & 0.48 & 0.16 & 0.89 & 0.45 & 0.48 & 0.77 & 0.23 & 0.41 & 0.12 \\
\hline Kirkos & 0.62 & 0.82 & 0.06 & 0.49 & 1.00 & 0.62 & 0.07 & 0.06 & 0.37 & 0.55 & 0.82 & 0.97 & 0.40 & 0.03 & 1.00 \\
\hline Nifas S. & 0.23 & 0.18 & 0.11 & 0.14 & 0.99 & 0.31 & 0.57 & 0.01 & 0.35 & 0.40 & 1.00 & 0.63 & 0.19 & 0.33 & 0.52 \\
\hline Akaki K. & 0.19 & 0.53 & 0.06 & 0.00 & 0.99 & 0.76 & 1.00 & 0.31 & 0.27 & 0.00 & 0.45 & 0.00 & 0.61 & 1.0 & 0.00 \\
\hline Bole & 0.35 & 0.1 & 0.00 & 0.04 & 0.99 & 0.00 & 0.75 & 0 & 0.00 & 1.00 & 0.77 & 0.41 & 1.00 & 0.00 & 0.09 \\
\hline Yeka & 0.00 & 0.13 & 0.32 & 0.10 & 0.00 & 0.82 & 0.48 & 1 & 0.60 & 0.32 & 0.75 & 0.54 & 0.04 & 1.09 & 0.26 \\
\hline Gulelle & 0.31 & 0 & 1.00 & 0.25 & 0.43 & 0.97 & 0.62 & 0.42 & 0.33 & 0.32 & 0.82 & 0.52 & 0.74 & 0.03 & 0.89 \\
\hline Kolfe & 0.23 & 0.1 & 0.44 & 0.19 & 0.84 & 0.62 & 0.81 & 0.27 & 0.61 & 0.43 & 0.61 & 0.54 & 0.00 & 1.0 & 0.51 \\
\hline SDV & 0.34 & 0.39 & 0.30 & 0.34 & 0.34 & 0.77 & 0.32 & 0.29 & 0.30 & 0.25 & 0.28 & 0.29 & 0.36 & 0.35 & 0.37 \\
\hline $1 / \mathrm{SDV}$ & 2.96 & 2.57 & 3.37 & 2.92 & 2.94 & 1.00 & 3.15 & 3.39 & 3.30 & 4.00 & 3.60 & 3.46 & 2.79 & 2.86 & 2.68 \\
\hline C & 0.02 & 0.02 & 0.02 & 0.02 & 0.02 & 0.87 & 0.02 & 0.02 & 0.02 & 0.02 & 0.02 & 0.02 & 0.02 & 0.02 & 0.02 \\
\hline Weight & 0.06 & 0.05 & 0.07 & 0.06 & 0.06 & 0.62 & 0.07 & 0.07 & 0.07 & 0.09 & 0.08 & 0.07 & 0.06 & 0.06 & 0.06 \\
\hline
\end{tabular}

Mean LST change(1), Air temperature change(2)Flood Risk(3), Population density(4), Forest cover(5), Mud(wood)house(6), Literacy Rate(7), Under five Mortality Rate(8), Unemployment Rate(9), Activity Rate(10), Access to tap(11), Access to toilets(12), Distance from emergency(13), Distance from health centers(14).Road Density(15) 


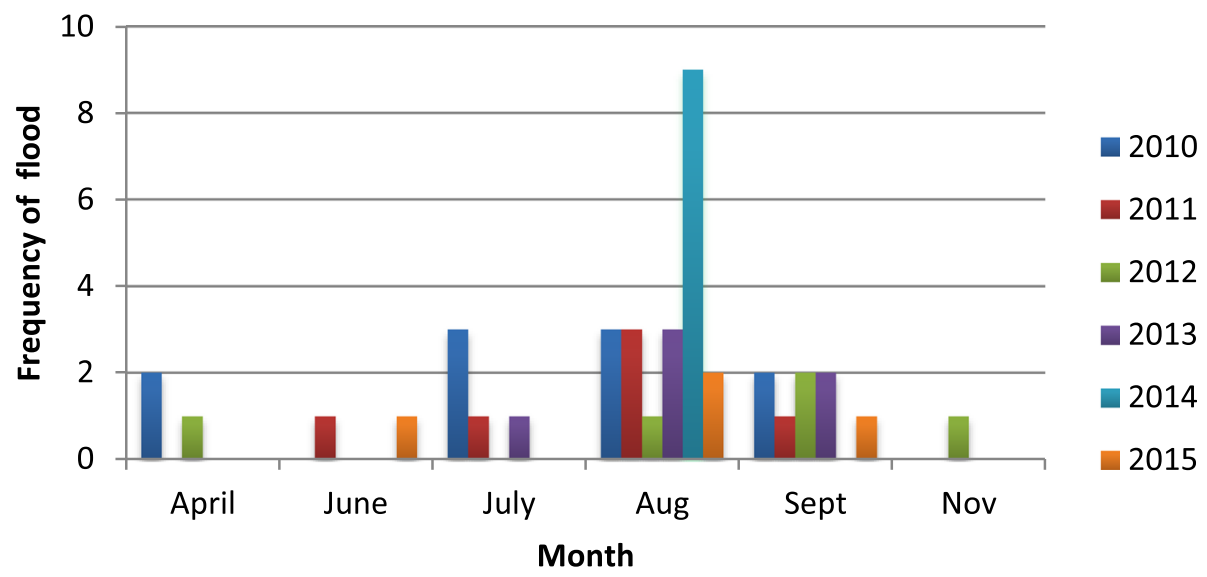

Fig. 8 Frequency of flood by months (2010-2015)

of economic development, low level of infrastructure, low level of access to basic needs, high rate of urbanization and unimplemented environmental plans.

The final vulnerability index, determined by composite indicators of exposure, sensitivity and adaptive capacity indicates that sub cities with vulnerability index more than 0.5 were Arada(0.63), Addis Ketema(0.60), Gulelle(0.53), Kirkos(0.52) and Lideta(0.5). Bole(0.45), Kolfe Keranio(0.4)and Nifas silk(0.37) were moderately vulnerable subcities, while Yeka $(0.33)$ and Akaki-Kality $(0.30)$ were the least vulnerable sub cities based on the selected 15 climate change vulnerability indicators.

\section{Conclusion}

This study tried to quantify, map and categorize climate change vulnerability in terms its sub contents of exposure, sensitivity and adaptive capacity. It considered 15 layers of vulnerability indicators with bio physical, social and economic layers at sub city level in Addis Ababa. The selections of the indicators are based on the literatures used to identify and map climate change vulnerability layers. Though it follows the IPCC'S climate change vulnerability analyses, the selection of the indicators were based on the Sullivan and Meigh's model which initially developed to prepare climate change vulnerability index.

Vulnerability to climate change is recognized as a state generated not just by climate change but by multiple processes and stressors. The stresses are more expressed by the low level development of adaptive capacity activities in Addis Ababa. Changes in adaptive capacity which mainly contained the socio economic analyses were rapidly changes, imposing a greatest effect on the impact of climate change vulnerability. Studies also suggest as the changes in the social causes of vulnerability often happen much more rapidly than many environmental changes(Khajuria and Ravindranath 2012.).
The overall arrangement of the vulnerability in Addis Ababa is determined by insufficient environmental management capacity. Highest vulnerability is due to extreme precipitation events, which mainly affects densely populated areas with low level of infrastructure development and low quality houses. Increases in temperature (both air and LST), as a result of urbanization activity and low land use management, will also continue to be a key concern for Addis Ababa's vulnerability to climate change in the future. A change in these two climatic elements plays a key role in determining the intensity and frequency of vulnerability.

Well implemented planning activity was confirmed to play a pivotal role in reducing impacts exerted by climate change; the exposure and sensitivity to climate change were confirmed to be high in densely populated areas with poor housing conditions,; temperature change was confirmed to be high in sub cities found in the northern and north western parts; the flooding risk was confirmed to be high in the areas of low slope and high population density; and the highest vulnerability at a sub cities with lower adaptation capacities. The integrated Sullivan and Meigh's Climate change vulnerability Index and the IPCC's definition of climate change vulnerability is well integrated in indicating and prioritizing vulnerable hot spots to climate change at sub city level.

Further studies have to be undertaken by adding additional indicators and recent data for better understanding and effective control of climate change vulnerability in Addis Ababa.

\section{Abbreviations}

CLUVA: Climate Change Vulnerability Assessment in Africa; CSA: Central Statistical Agency; CVI: Climate Change Vulnerability Index; DEM: Digital Elevation Model; FAO: Food and Agriculture Organization; GCM: General Circulation Models; GDP: Gross Domestic Product; ICRISAT: International Crops Research Institute for the Semi-Arid Tropics; IPCC: Intergovernmental Panel on Climate Change; LST: Land Surface Temperature 


\section{Acknowledgements}

The authors would like to thank German Academic Exchange Service (DAAD) for providing in country scholarship to the corresponding author for his Ph.D study at Addis Ababa University, Ethiopian Institute of Architecture, Building Constriction and Urban Development. The authors would also like to thank Potsdam Institute for Climate Impact Research, for allowing a corresponding author a 6 month research visit in Potsdam Institute for Climate Impact Research, Potsdam Germany. The USGS website that allowed the authors to download the Landsat images freely from their archives should also be acknowledged. The authors would also like to thank the Central statistical Agency of Ethiopia for providing us population and socio economic data.

\section{Funding}

The first author is grateful to DAAD East Africa In country/In Region Scholarship funding programme number 57220758 , for the PhD scholarship fund and Addis Ababa University, for Thematic Area Research Fund, fund number TR/11/2013.

\section{Availability of data and materials}

Authors declare that the data and materials presented in this manuscript can be made publically available by Springer Open as per the editorial policy.

\section{Authors' contributions}

All authors read, helped to edit, and approved the final manuscript.

\section{Competing interests}

The authors declare that they have no competing interests.

\section{Publisher's Note}

Springer Nature remains neutral with regard to jurisdictional claims in published maps and institutional affiliations.

\section{Author details}

${ }^{1}$ Ethiopian Institute of Architecture, Building Construction and City Development (EiABC), Environmental Planning Programme, Addis Ababa University, P.O. Box 518, Dej. Balcha Aba Nefso St, Addis Ababa, Ethiopia. ${ }^{2}$ Ethiopian Institute of Architecture Building Construction and City Development (EiABC), Addis Ababa University, Addis Ababa, Ethiopia. ${ }^{3}$ Water and Land Resource Center, Addis Ababa, Ethiopia. ${ }^{4}$ Ethiopian Institute of Architecture Building Construction and City Development (EiABC), Addis Ababa University, Addis Ababa, Ethiopia. ${ }^{5}$ Department of Geography and Environmental Studies, Addis Ababa University, Addis Ababa, Ethiopia.

Received: 9 May 2018 Accepted: 5 September 2018

Published online: 21 September 2018

\section{References}

Abebe, E., and A. Kebede. 2017. Assessment of climate change impacts on the water resources of Megech River catchment, Abbay Basin. Ethiopia Open Journal of Modern Hydrology. 07 (2). https://doi.org/10.4236/ojmh.2017.72008.

Adger, W.N., N.W. Arnell, and E.L. Tompkins. 2005. Successful adaptation to climate change across scales. Global Environmental Change 15 (2): 75-86. https://doi.org/10.1016/j.gloenvcha.2004.12.005.

Amare, A., and B. Simane. 2017. Determinants of smallholder farmers' decision to adopt adaptation options to climate change and variability in the Muger sub basin of the upper Blue Nile basin of Ethiopia. Agric \& Food Secur 6 (64). https://doi.org/10.1186/s40066-017-0144-2.

Belete, D.H. 2011. Road and urban storm water drainage network integration in Addis Ababa: Addis Ketema sub-city. Journal of Engineering and Technology Research 3 (7): 217-225 http://www.academicjournals.org/article/ article1380190860_Belete.pdf.

Billi, P., Y. Alemu, and R. Ciampalini. 2015. Increased frequency of flash floods in Dire Dawa, Ethiopia: Change in rainfall intensity or human impact? Natural Hazards 76 (2): 1373-1394. https://doi.org/10.1007/s11069-014-1554-0.

Birhanu, D., H. Kima, C. Jang, and S. Park. 2016. Flood risk and vulnerability of Addis Ababa City due to climate change and urbanization. Procedia Engineering 154: 696-702. https://doi.org/10.1016/j.proeng.2016.07.571.

Climate change and Urban Vulnerability in Africa. 2011. Assessing vulnerability of urban systems. In Populations and goods in relation to natural and man-made disasters in Africa http://www.cluva.eu/CLUVA_publications/CLUVA_Climate-
change-and-vulnerability-of-African-cities-Research-briefs.pdf. Accessed Dec 2014.

Cochrane, L., and P. Costolanski. 2013. Climate change vulnerability and adaptability in an urban context: A case study of Addis Ababa, Ethiopia. International Journal of Sociology and Anthropology. 5 (6): 192-204. https:// doi.org/10.5897/JSSA2013.0459.

Conway, D., and L.E.F. Schipper. 2011. Adaptation to climate change in Ethiopia: Opportunities identified from Ethiopia. Global Environmental Change 21 (1): 227-237. https://doi.org/10.1016/j.gloenvcha.2010.07.013.

De Sherbinin, A. 2014. Climate change hotspots mapping: What have we learned? Climatic Change 123 (1): 23-37. https://doi.org/10.1007/s10584-0130900-7.

Doll, P. 2009. Vulnerability to the impact of climate change on renewable groundwater resources: A global-scale assessment. Environmental Research Letters 4 (1). https://doi.org/10.1088/1748-9326/4/3/035006.

Federal Democratic Republic of Ethiopia Central Statistical Agency. 2013. Population projection of Ethiopia for all regions at Wereda level from 20142017. https://www.academia.edu/30252151/Federal_Democratic_Republic_ of_Ethiopia_Central_Statistical_Agency_Population_Projection_of_Ethiopia_ for_All_Regions_At_Wereda_Level_from_2014_2017. Accessed Mar 2017.

Feyissa, G., G. Zeleke, W. Bewket, and E. Gebremariam. 2018. Downscaling of future temperature and precipitation extremes in Addis Ababa under climate change. Climate. 6: 58.

Folke, C., S. Carpenter, T. Elmqvist, L. Gunderson, C.S. Holling, and B. Walker. 2002. Resilience and sustainable development: Building adaptive capacity in a world of transformations. A Journal of the Human Environment 31 (5): 437440. https://doi.org/10.1579/0044-7447-31.5.437.

Fussel, H.M., and J.T. Klein. 2006. Climate change vulnerability assessments. Climatic Change 75: 301-329 https://link.springer.com/article/10.1007/s10584006-0329-3.

Gebreegziabher Z, Mekonnen A, Deribe, R, Boka, J, Abera S. 2016. Mapping vulnerability to climate change of the farming sector in the Nile Basin of Ethiopia. A micro-level perspective. Environment for development. http:// www.efdinitiative.org/sites/default/files/publications/efd-dp-16-19_0.pdf. Accessed Aug 2017.

Hassaan, M.A., M.A. Abdrabo, and P. Masabarakiza. 2017. GIS-based model for mapping malaria risk under climate change case study: Burundi. Journal of Geoscience and Environment Protection 5: 102-117. https://doi.org/10.4236/ gep.2017.511008.

Intergovernmental Panel on Climate Change. 2014. Climate change 2014 Impacts, adaptation, and vulnerability WGII AR5 summary for policymakers. http://www.ipcc.ch/report/ar5/wg2/. Accessed Dec 2016.

International Crops Research Institute for the Semi-Arid Tropics. 2009. Quantitative assessment of vulnerability to climate change from URL: http://danida.vnu.edu. vn/cpis/files/Papers_on_CCNulnerability/Quantitative\%20assessment\%20of\%20 Vulnerability\%20to\%20Climate\%20Change.pdf. Accessed Apr 2012.

lyengar, N.S., and P. Sudarshan. 1982. A method of classifying regions from multivariate data. Economic and Political Weekly 17: 2048-2052 http://www. epw.in/journal/1982/51/special-articles/method-classifying-regionsmultivariate-data.html.

Khajuria, A., and N.H. Ravindranath. 2012. Climate change vulnerability assessment: Approaches DPSIR framework and vulnerability index. Journal of Earth Science and Climatic Change 3 (1). https://doi.org/10.4172/2157-7617. 1000109

Legesse, S.A., P. Rao, and N. Rao. 2016. Statistical downscaling of daily temperature and rainfall data from global circulation models: In South Wollo zone, North Central Ethiopia. National Monthly Refereed Journal of Res. in Science \& Tech 2 (7): 27-39.

Malone, Battelle. 2009. Vulnerability and resilience in the face of climate change: Current research and needs for population information. Washington: Pacific Northwest Division Richland http://www.globalchange.umd.edu/data/ publications/Resilience_and_Climate_Change.pdf.

McSweeney C., New, M., Lizcano, G. 2010. UNDP climate change country profiles: Ethiopia. https://digital.library.unt.edu/ark:/67531/metadc226682/. Accessed Aug 2015.

Melese, S. 2016. Effect of climate change on water resources. Journal of Water Resources and Ocean Science. 5 (1). https://doi.org/10.11648/j.wros.20160501.12.

Moser, C., A. Norton, A. Stein, and S. Georgieva. 2010. Pro-poor adaptation to climate change in urban Centres: Case studies of vulnerability and resilience in Kenya and Nicaragua. In Social development department report 54947-GLB. Washington: World Bank. 
Moss, R.H., A.L. Brenkert, and E.L. Malone. 2001. Vulnerability to climate change: A quantitative approach. Richland: Technical Report PNNL-SA-33642, Pacific Northwest National Laboratories.

Mwangi, K.M., and F. Mutua. 2015. Modeling Kenya's vulnerability to climate change - A multifactor approach. International Journal of Science and Research (IJSR) ISSN (Online): 2319-7064 http://www.ijsr.net/archive/v4i6/SUB155079.pdf. Accessed Sept 2015

Nasiri, H., and S. Shahmohammadi-Kalalagh. 2013. Flood vulnerability index as a knowledge base for flood risk assessment in urban area. Journal of Novel Applied Science 2: 269-272.

Olatona, O. 2017. Mapping of flood risk zones in Ala River basin Akure, Nigeria. American Journal of Applied Sciences and Engineering http://thescipub.com/ abstract/10.3844/ofsp.11774

Ouma, Y., and R. Tateishi. 2014. Urban flood vulnerability and risk mapping using integrated multi-parametric AHP and GIS: Methodological overview and case study assessment. Water Journal. https://doi.org/10.3390/w6061515.

Rahmana, M. 2016. Land use and land cover changes and urban sprawl in Riyadh, Saudi Arabia: An analysis using multi-temporal Landsat data and Shannon's entropy index. The International Archives of the Photogrammetry, Remote Sensing and Spatial Information Sciences XLI-B8: 1017-1021. https:// doi.org/10.5194/isprs-archives-XLI-B8-1017-2016

Shemsanga, C., A.N. Omambia, and Y. Gu. 2010. The cost of climate change in Tanzania: Impacts and adaptations. Journal of American Science 6 (3): 182-196 http://www.jofamericanscience.org/journals/am-sci/am0603/24_2189_ climate_am0603_182_196.pdf.

Sierra-Soler, A., J. Adamowsk, Z. Qi, H. Saadat, and S. Pingale. 2015. High accuracy land use land cover (LULC) maps for detecting agricultural drought effects in Rainfed agro-ecosystems in Central Mexico. Journal of Water and Land Development and Environmental Engineering in Agriculture 26 (Vii-|x): 19-35. https://doi.org/10.1515/jwld-2015-0014.

Smit, B., and J. Wandel. 2006. Adaptation, adaptive capacity and vulnerability. Global Environmental Change 16: 282-292 http://citeseerx.ist.psu.edu/ viewdoc/download?doi=10.1.1.174.5145\&rep=rep1\&type=pdf.

Srivastava, A. 2015. Report on the patterns of disaster risk reduction actions at local level. Vulnerability to climate change \& variability: An investigation into macro \& micro level assessments - A case study of agriculture sector in Himachal Pradesh, India. http://www.unisdr.org/campaign/resilientcities/ assets/documents/privatepages/ VULNERABILITY\%20TO\%20CLIMATE\%20CHANGE\%20\&\%20VARIABILITY.pdf.

Sullivan, C., and J. Meigh. 2005. Targeting attention on local vulnerabilities using an integrated index approach: The example of the climate vulnerability index. Water Science and Technology 51 (5): 69-78 https://www.ncbi.nlm.nih. gov/pubmed/15918360

Tafesse, A., G. Ayele, M. Ketema, and E. Geta. 2016. Food security and vulnerability to climate change in eastern Ethiopia. Economics. 5 (6): 81-88. https://doi. org/10.11648/j.eco.20160506.11.

Teferi, E., and H. Abraha. 2017. Urban Heat Island effect of Addis Ababa City: Implications of urban green spaces for climate change adaptation. Climate Change Adaptation in Africa, Climate Change Management. https://doi.org/10. 1007/978-3-319-49520-0_33.

United Nations Development Programme. 2006. Human development report 2006. Beyond scarcity: Power, poverty and the global water crisis. http://hdr. undp.org/sites/default/files/reports/267/hdr06-complete.pdf. Assessed June 2015.

United Nations Habitat. 2003. Urban inequities report. Addis Ababa, cities and citizens series.

Ward P, and Lasage R. 2009. Downscaled climate change data from the HADCM3 and ECHAM5 models on precipitation and temperature for Ethiopia and Kenya. Institute for Environmental Studies, Vrije Universiteit. Netherlands.

Woldegerima, T., K. Yeshitela, and S. Lindley. 2016. Characterizing the urban environment through urban morphology types (UMTs) mapping and land surface cover analysis: The case of Addis Ababa, Ethiopia. Urban Ecosystem. 19 (2): 245-263. https://doi.org/10.1007/s11252-016-0590-9.

Woodruff, S., K. Vitro, and T. BenDor. 2017. GIS and coastal vulnerability to climate change, 236-257. Chapel Hill: University of North Carolina at Chapel Hill. https://doi.org/10.1016/B978-0-12-409548-9.09655-X.

World Bank. 2015. Enhancing urban resilience Addis Ababa, Ethiopia. https:// www.gfdrr.org/sites/default/files/publication/Addis_Ababa_Resilient_cities_ program.pdf. Accessed 15 Sept 2016.
Youneszadeh, S., N. Amiri, and P. Pilesjö. 2015. The effect of land use change on land surface temperature in the Netherlands. The international archives of the photogrammetry. Remote Sensing and Spatial Information Sciences XL-1/ W5: 745-748.

Zurovec, H.G., S. Cadro, and B.K. Sitaula. 2017. Quantitative assessment of vulnerability to climate change in rural municipalities of Bosnia and Herzegovina. Sustainability 9 (7): 1208. https://doi.org/10.3390/su9071208.

\section{Submit your manuscript to a SpringerOpen ${ }^{\circ}$ journal and benefit from:}

- Convenient online submission

- Rigorous peer review

- Open access: articles freely available online

- High visibility within the field

- Retaining the copyright to your article

Submit your next manuscript at $>$ springeropen.com 